\title{
O uso indiscriminado de antimicrobianos para o desenvolvimento de micro-organismos resistentes
}

The indiscriminate use of antimicrobials for the development of resistant microorganisms

\author{
El uso indiscriminado de antimicrobianos para el desarrollo de microorganismos \\ resistentes
}

Roberta Farias dos Santos Monteiro ${ }^{1 *}$, Valéria Ribeiro Rosa dos Santos ${ }^{1}$, Alice Aparecida Costa Turetta Ferrreira ${ }^{1}$, José Roberto Gonçalves de Abreu ${ }^{1}$.

\section{RESUMO}

Objetivo: Avaliar os riscos que todo paciente ou pessoa comum se expõe diante do uso indiscriminado de antimicrobianos no tratamento de infecções. Métodos: Trata-se de uma revisão integrativa de literatura cuja pesquisa bibliográfica, teve como foco o risco do uso indiscriminado de antimicrobianos frente a possibilidade de resistência bacteriana. Realizou-se uma retrospectiva tendo como base o banco de dados da Literatura Latino-americana e do Caribe em Ciências da Saúde (LILACS), Medical Literature Analysis and Retrieval System Online (MEDLINE) e o repositório Scientific Electronic Library Online. A Scientific Electronic Library Online (SCIELO). Resultados: Percebe-se o mau uso dos antibióticos para tratamento e profilaxia de infecções pelos resultados negatives na redução da sua eficácia e variações da sensibilidade das bactérias diante desses medicamentos, o que torna o controle do uso de antimicrobianos, pela ciência e profissionais de saúde, desafiador e relevante para proteção da população diante da resistência que os microorganismos tem desenvolvido. Considerações finais: A resistência bacteriana, originada pelo uso indiscriminado de antimicrobianos, é uma questão de saúde pública pelo aumento na morbidade e mortalidade que causa em todo mundo. O Brasil tem buscado controlar a venda livre desses medicamentos através do Sistema Nacional de Gerenciamento de Produtos Controlados (SNGPC) para evitar que seu uso inapropriado concorra para o processo de resistência bacteriana.

Palavras-chave: Antimicrobianos, Microorganismos, Infecções.

\begin{abstract}
Objective: To assess the risks that every patient or ordinary person is exposed to due to the indiscriminate use of antimicrobials in the treatment of infections. Methods: This is an integrative literature review whose bibliographic research focused on the risk of indiscriminate use of antimicrobials in view of the possibility of bacterial resistance. A retrospective was carried out based on the database of Latin American and Caribbean Literature in Health Sciences (LILACS), Medical Literature Analysis and Retrieval System Online (MEDLINE) and the Scientific Electronic Library Online repository. The Scientific Electronic Library Online (SCIELO). Results: The misuse of antibiotics for the treatment and prophylaxis of infections is perceived by the negative results in reducing their effectiveness and variations in the sensitivity of bacteria to these drugs, which makes the control of the use of antimicrobials by science and health professionals, challenging and relevant for the protection of the population in the face of the resistance that microorganisms have developed. Final considerations: Bacterial resistance, caused by the indiscriminate use of antimicrobials, is
\end{abstract}

${ }^{1}$ Faculdade Vale do Cricaré, São Mateus - ES. `E-mail: robertafasa@hotmail.com 
a public health issue due to the increase in morbidity and mortality it causes worldwide. Brazil has sought to control the free sale of these drugs through the National Controlled Products Management System (SNGPC) to prevent their inappropriate use from contributing to the bacterial resistance process.

Keywords: Antimicrobials, Microorganisms, Infections.

\section{RESUMEN}

Objetivo: evaluar los riesgos a los que está expuesto cada paciente o persona común en el uso indiscriminado de antimicrobianos en el tratamiento de infecciones. Métodos: Esta es una revisión bibliográfica integradora cuya investigación bibliográfica se centró en el riesgo de uso indiscriminado de antimicrobianos en vista de la posibilidad de resistencia bacteriana. Se realizó una retrospectiva basada en la base de datos de Literatura Latinoamericana y del Caribe en Ciencias de la Salud (LILACS), el Sistema de Análisis y Recuperación de Literatura Médica en línea (MEDLINE) y el repositorio en línea de la Biblioteca Electrónica Científica. The Scientific Electronic Library Online (SCIELO). Resultados: El uso indebido de antibióticos para el tratamiento y la profilaxis de infecciones se percibe por los resultados negativos en la reducción de su efectividad y las variaciones en la sensibilidad de las bacterias a estos medicamentos, lo que hace que el control del uso de antimicrobianos por parte de los científicos y profesionales de la salud, desafiante y relevante para la protección de la población frente a la resistencia que los microorganismos han desarrollado. Consideraciones finales: La resistencia bacteriana, causada por el uso indiscriminado de antimicrobianos, es un problema de salud pública debido al aumento en la morbilidad y mortalidad que causa en todo el mundo. Brasil ha tratado de controlar la venta gratuita de estos medicamentos a través del Sistema Nacional de Gestión de Productos Controlados (SNGPC) para evitar que su uso inapropiado contribuya al proceso de resistencia bacteriana.

Palabras clave: Antimicrobianos, Microorganismos, Infecciones.

\section{INTRODUÇÃO}

No tratamento de bactérias causadoras de várias doenças, o uso indiscriminado de antimicrobianos não específicos, apesar da ação positiva que conseguem sobre um grande número de bactérias, podem causar sérios problemas nos tratamentos futuros. Trabulsi LR e Alterthum $F(2011)$ esclarecem que 0 uso de antimicrobianos não específicos, embora eficazes no combate a muitas bactérias, acabam por destruir outras que também não deveriam, levando à chamada resistencia bacteriana.

Rossi F e Andreazzi DB (2005) destacam que não existe um vazio no universo bacteriano, uma vez que, no momento em que algumas cepas bacterianas são destruídas, outras, necessariamente mais fortes e melhoradas geneticamente, ocuparão o espaço deixado. Essa realidade se tornou hoje um grande problema de saúde pública, principalmente pela larga escala de uso de antimicrobianos que vem favorecendo o aparecimento das chamadas cepas bacterianas resistentes.

Assim esse estudo vem desenvolver essa linha de discussão que envolve a temática da importância do controle do uso dos antimicrobianos, no caso do Brasil pelo Sistema Nacional de Gerenciamento de Produtos Controlados (SNGPC), como forma de controle e eficácia no combate ao desenvolvimento de bactérias resistentes.

A justificativa para o desenvolvimento desse tema se pauta na necessidade urgente de esclarecer e discutir informações relevantes que ajudem no controle e uso adequado de antimicrobianos, medicamentos que fazem parte do cotidiano da população mundial e que, se usados indevidamente, podem comprometer gravemente sua eficácia no tratamento de infecções. Essa importância se confirma através dos dados estatísticos retratados por Trabulsi LR, et al. (2006) originados da Organização Mundial da Saúde (OMS) sobre a influência direta das infecções nas mortes causadas em todo mundo chegando a assustadores $25 \%$ delas nos países desenvolvidos e $45 \%$ em países menos desenvolvidos, retratando que mais de $50 \%$ das 
prescrições se mostram inapropriadas; $2 / 3$ dos antibióticos são usados sem prescrição médica em muitos países; $50 \%$ dos consumidores compram medicamento para um dia; $90 \%$ compram-no para period igualou inferior a 3 dias e mais de $50 \%$ do orçamento com medicamentos são destinados aos antimicrobianos.

Para Bisson MP (2003) no tratamento de uma infecção, a escolha, dosagem, via de administração e tempo de tratamento do antimicrobiano, podem representar a eficiência da terapêutica. Nem sempre é possível definir o agente etiológico e o consequente antibiograma. Portanto, afirma o autor, a escolha do antibiotic deve considerar o local de ação, a flora bacteriana normal neste, os prováveis agents etiológicos, perfil de sensibilidade, resistência dos microrganismos aos agentes antimicrobianos e o custo dos mesmos.

Daí a necessidade desse trabalho problematizar o tema em foco levantando o seguinte questionamento: qual o risco a que todo paciente ou pessoa comum se expõe diante do uso indiscriminado de antimicrobianos no tratamento de infecções?

Como objetivo maior deste estudo buscar-se-á discutir o risco a que todo paciente ou pessoa comum se expõe diante do uso indiscriminado de antimicrobianos no tratamento de infecções concorrendo para 0 desenvolvimento de micro-organismos resistentes.

\section{MÉTODOS}

Quanto à metodologia realizou-se neste estudo uma revisão integrativa da literatura, cuja questão condutora da pesquisa foi se discutir 0 uso indiscriminado de antimicrobianos concorrendo para 0 desenvolvimento de micro-organismos resistentes.

Para a busca dos artigos foram utilizadas as seguintes bases de dados: da Literatura Latino-Americana e do Caribe em Ciências da Saúde (Lilacs), Medical Literature Analysis and Retrieval System on-line (Medline) e o repositório Scientific Electronic Library Online (Scielo, além de livros cujo conteúdo tivessem temas ligados de forma direta ao objetivo deste trabalho.

Para o levantamento dos artigos utilizou-se como descritores: Antimicrobianos, microorganismos e infecções. Inicialmente, realizou-se a busca pelos descritores individualmente, sendo, em seguida, realizados os cruzamentos utilizando o operador boleanoand. Posteriormente, os descritores foram cruzados em conjunto. Os critérios de inclusão para a seleção da amostra foram: artigos publicados em português, publicados e indexados nas referidas bases de dados, nos últimos 20 anos e que retratassem a temática em estudo.

Lançou-se mão nesta revisão integrativa de estratégias para levantar dados dos artigos de forma adaptada a cada uma das bases de dados, de acordo com as especificidades de acesso guiadas pela pergunta condutora e critérios de inclusão. Quando da seleção dos artigos, obviamente, todos os títulos que tinham relação com o objetivo do estudo para, em seguida, olhar-se os resumos e escolher na íntegra os que estavam relacionados com a temática em estudo.

A realização dos levantamentos bibliográficos deu-se de março a maio de $2020 \mathrm{com}$ os artigos encontrados enumerados de acordo com as normas de referência bibliográfica. Para análise dos dados foram criadas categorias temáticas de acordo com o agrupamento dos conteúdos encontrados, referentes ao uso indiscriminado de antimicrobianos para o desenvolvimento de micro-organismos resistentes. 
Figura 1 - Critérios de inclusão e exclusão estabelecidos para o estudo.
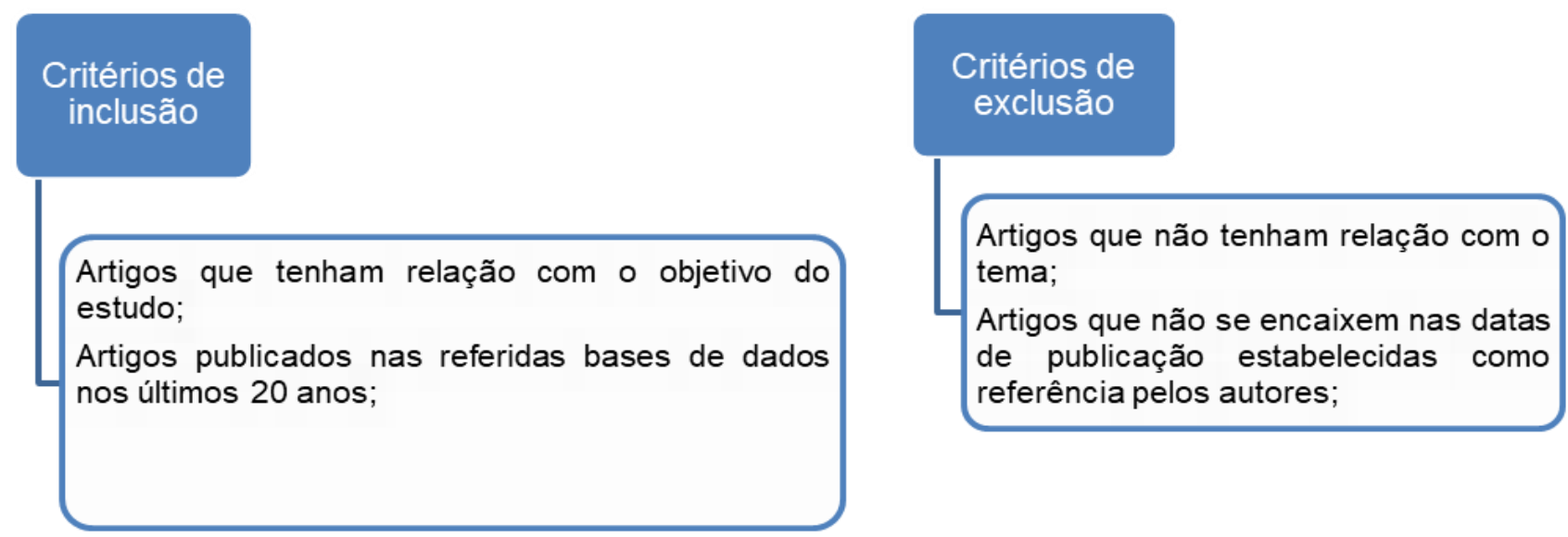

Fonte: Monteiro RFS, et al., 2020.

A realização dos levantamentos bibliográficos ocorreu no período de janeiro a março de 2020 , sendo as fontes encontradas enumeradas conforme a ordem de localização, identificados e apresentados de acordo as normas de referência bibliográfica.

\section{RESULTADO E DISCUSSÃO}

Quadro 1 - Dialogando com as pesquisas na área.

\begin{tabular}{|c|c|}
\hline Autor/Ano & Objetivo/Resultados \\
\hline $\begin{array}{l}\text { logia (Trabulsi LR e } \\
\text { n F, 2011) }\end{array}$ & $\begin{array}{l}\text { Abordar aspectos básicos do conhecimento dos micro-org } \\
\text { forma, estrutura, fisiologia, crescimento e genética. A } \\
\text { antimicrobianos (antibióticos e quimioterápicos) de ação } \\
\text { antifúngica e antiviral são amplamente apresentados e dis } \\
\text { como a interacão patógeno/hospedeiro. }\end{array}$ \\
\hline \begin{tabular}{lrr|} 
Jso indiscriminado & de \\
antibióticos & e & resistência \\
nicrobiana: & uma & Guerra \\
berdida? (Wannmacher L, 2004)
\end{tabular} & $\begin{array}{l}\text { Destacar que a grande disponil } \\
\text { publicidade pouco judiciosa, ace } \\
\text { agravando as doenças infecciosas, } \\
\text { usando-se alternativas antimicrobia } \\
\text { hospitalizações. }\end{array}$ \\
\hline $\begin{array}{l}\text { ic use in eastern Europe: } \\
\text {-national database study } \\
\text { dination with the WHO } \\
\text { al Office for Europe } \\
\text { rten A, et al, 2014) }\end{array}$ & $\begin{array}{l}\text { uso } \\
\text { e não } \\
\text { lentes }\end{array}$ \\
\hline $\begin{array}{l}\text { Perfil de prescrições e uso de } \\
\text { antibióticos em infecções } \\
\text { comunitárias (Fiol FSD et al, } \\
\text { 2010). }\end{array}$ & $\begin{array}{l}\text { de } \\
\text { a e }\end{array}$ \\
\hline $\begin{array}{l}\text { xcessive antibiotic use for } \\
\text { zute respiratory infections in } \\
\text { e United States (Gonzales R } \\
\text { al, 2011). }\end{array}$ & $\begin{array}{l}\text { icos na } \\
\text { o maior } \\
\text { rvenção }\end{array}$ \\
\hline $\begin{array}{l}\text { Farmácia Clínica e } \\
\text { Farmacêutica } \\
\text { 2003). }\end{array}$ & $\begin{array}{l}\text { rmacoterapêuticos } \\
\text { te ao tratamento, } \\
\text { monitora reações } \\
\text { qualidade de vida }\end{array}$ \\
\hline
\end{tabular}

Fonte: Monteiro RFS, et al., 2020. 


\section{Bactérias resistentes: um desafio real}

O uso indiscriminado de antimicrobianos tem tornado o papel da ciência e dos profissionais de saúde a cada dia mais difícil e desafiador no que diz respeito ao controle das infecções que acometem grande parte da população, principalmente pela resistência que esses micro-organismos vêm desenvolvendo em face desse procedimento perigoso.

Em um relatório divulgado a Organização Mundial de Saúde (OMS) considera a resistência dos antimicrobianos um problema de relevância mundial, tornando-se uma ameaça para a atenção aos pacientes e para o controle das doenças em todo o mundo. Sua preocupação com essa situação fez com que ela contemplasse esta problemática como tema relevante no dia Mundial da Saúde de forma a dar visibilidade a este problema que assola os serviços de saúde mostrando que não é novo e que se torna cada vez mais importante (OMS, 2011).

Segundo Trabulsi LR e Alterthum F (2011) recentes estudos desenvolvidos por grandes laboratórios de renome internacional têm revelado que a maioria dos antimicrobianos que foram desenvolvidos para o controle de muitas bactérias causadoras de infecções acabou tornando-as mais resistentes e induzindo ao surgimento de bactérias tão resistentes que os atuais antimicrobianos criados para combatê-las se tornaram ineficazes, o que acaba elevando essa situação ao status de problema de saúde.

Dessa forma, torna-se imprescindível a atuação do sistema de vigilância epidemiológica e seus métodos de controle de venda e comercialização desses medicamentos, onde destaca-se o Sistema Nacional de Gerenciamento de Produtos Controlado (SNGPC) brasileiro, controlado pela Agência de Vigilância Sanitária (ANVISA).

Trata-se de um programa de implementação de medidas que, segundo Wannmacher L (2004), é necessário para se interferir nos resultados e reduzir as já altas taxas de prevalência de infecção hospitalar e minimizar a seleção microbiótica que nos últimos anos vem crescendo em ritmo acelerado e proporcional ao desenvolvimento de novas drogas de amplo espectro. Versporten A, et al. (2014) alerta que é possível reduzir a prescrição de antibióticos em muitas das infecções atualmente tratadas de forma desnecessária sem comprometer a saúde dos indivíduos e causando menos danos. No quadro 1 ele alerta para os riscos potenciais que corre o indivíduo que faz uso excessivo de antimicrobianos para o tratamento de infecções.

Quadro 2 - Riscos associados ao uso excessivo de antibióticos.

\begin{tabular}{|c|}
\hline Aumento da resistência antimicrobiana \\
\hline Aumento de doenças mais graves \\
\hline Aumento do comprimento da doença \\
\hline Aumento do risco de complicações \\
\hline Aumento da taxa de mortalidade \\
\hline Aumento dos custos com saúde \\
\hline Aumento do risco de efeitos adversos, alguns com risco de vida \\
\hline Aumento de re-atendimento devido a doenças infecciosas \\
\hline Aumento da medicalização de condições infecciosas autolimitantes \\
\hline
\end{tabular}

Fonte: Monteiro RFS, et al., 2020.Baseado em Versporten A, et al., 2014.

Oliveira AC, et al. (1998) já destacavam o crescimento de estudos relacionados ao surgimento de bactérias resistentes nos últimos anos paralelamente às preocupações das autoridades governamentais sobre o uso de antimicrobianos, o que reflete a necessidade de medidas de atenção quanto ao mau uso desses fármacos e a aquisição de resistência em relação a eles por micro-organismos causadores de infecções, devido, em especial, ao seu mau uso pela população.

Para Oliveira AC et al. (1998) o processo de multirresistência bacteriana constitui o fator básico que corrói a eficácia futura dos novos antimicrobianos e que fundamenta a investigação e produção de novas 
drogas. Daí torna-se mais fácil o entendimento da história dos antimicrobianos que tem se caracterizado pela dinâmica e frequente sobreposição de novos desafios que resultam no desenvolvimento contínuo de drogas cada vez mais potentes e de um espectro de ação cada vez mais ampliado.

O mesmo relatório divulgado pela Organização Mundial da Saúde (OMS, 2011) revela que mais de 50\% das prescrições de antimicrobianos, a época, eram inapropriadas. Em consequência desse uso indiscriminado é refletida no aumento dos custos e da indução da pressão seletiva de patógenos resistentes e efeitos adversos.

Reiterando esses dados Fiol FSD, et al. (2010) afirma que, somente nos Estados Unidos, o custo com resistência bacteriana gira em torno de 4 a 5 bilhões de dólares anuais enquanto no Brasil esses números ultrapassam a casa de 1 bilhão de reais.

O cenário do uso indiscriminado de antimicrobianos no Brasil é descrito por Wannmacher $L$ (2004) como mais sério pelo fato desses produtos ainda se encontrarem sendo vendidos livremente no comércio e as medidas para o controle de uso nos hospitais serem consideradas inconsistentes. A alta disponibilidade e o consumo de antimicrobianos têm sido uma combinação perigosa que vem gerando um aumento desproporcional da incidência do uso inapropriado dessas drogas e concorrendo para o processo de resistência bacteriana.

\section{O perigo do uso indiscriminado de antimicrobianos como fator preponderante para o desenvolvimento de micro-organismos resistentes}

Segundo a Who (2000), a situação emergencial de aparecimento de resistência aos antibióticos é considerada por muitos especialistas da área da microbiologia como uma das mais importantes ameaças à saúde humana no século XXI. De acordo com Bonten MJM, et al. (2001), a resistência microbiana, ao mesmo tempo que se tornou um fenômeno mundial digno de ser estudado dentro do universe científico da microbiologia, tornou-se um importante problema de saúde pública devido à má e negligente utilização dos antibióticos.

Como muitos casos passaram a acontecer nas décadas seguintes, acabou-se dando origem a um grave problema de saúde pública, com implicações sociais e políticas que, segundo WHO (2000) são transnacionais e atravessam todas as fronteiras possíveis, momento em que ela construiu uma espécie de ABC para orientar os profissionais de saúde e a população sobre o mecanismo de resistência dos antimicrobianos (Quadro 2).

Quadro 3 - O ABC da resistência.

\begin{tabular}{|c|r|}
\hline Estágio 1 & Os antibióticos permitem grandes progressos na medicina; \\
\hline Estágio 2 & O mau uso dos antibióticos leva ao aparecimento de bactérias resistentes; \\
\hline Estágio 3 & As bactérias resistentes acumulam-se e disseminam-se; \\
\hline Estágio 4 & $\begin{array}{r}\text { As bactérias aumentam as complicações clínicas, levam ao prolongamento da } \\
\text { estadia hospitalar e aumentam os custos; }\end{array}$ \\
\hline Estágio 5 & O desenvolvimento de novos antibióticos é lento, caro e não pode ser garantido. \\
\hline Estágio 6 & $\begin{array}{r}\text { Com o aumento das resistências e menos agentes microbianos novos, a medicina } \\
\text { moderna enfrentará retrocessos significativos. }\end{array}$ \\
\hline
\end{tabular}

Fonte: Monteiro RFS, et al., 2020. Baseado em WHO (2001).

Para Gonzales R, et al. (2011) o uso generalizado, e muitas vezes inadequado, de agentes antimicrobianos é a causa mais importante do surgimento da resistência a medicamentos, tanto na comunidade como nos hospitais. A exposição prévia a antibióticos demonstrou ser o fator de risco mais frequente para o desenvolvimento de infecções respiratórias adquiridas na comunidade causadas por streptococcus pneumoniae resistente a medicamentos. Isso não é surpreendente, porque as doenças respiratórias agudas superiores representam a maior proporção de prescrições ambulatoriais de antibióticos, sendo a maioria dispensada em situações nas quais os antibióticos nem eram indicados. 
Na visão de Vandenbroucke-Grauls CMJE (2003) a resistência antimicrobiana tornou-se rapidamente um desafio significativo para a saúde global, porque vários organismos comuns nosocomiais e adquiridos na comunidade desenvolveram resistência a medicamentos que pode ter um impacto substancial nos cuidados de saúde, afetando adversamente a morbimortalidade e melhorando as oportunidades de transmissão de doenças devido à falha do tratamento, além do aumento dos custos.

Para Berman S (2001) em nenhum lugar esse fenômeno é tão desafiador quanto nos países em desenvolvimento, onde o uso de antibióticos é freqüentemente mal controlado e o ônus das doenças infecciosas é maior. No entanto, poucas informações confiáveis sobre os padrões de resistência antimicrobiana no mundo em desenvolvimento estão disponíveis para orientar o tratamento e as políticas de saúde pública, o que faz da resistência antimicrobiana um desafio especial para o tratamento e controle de infecções respiratórias agudas, a principal causa de morte em crianças em todo o mundo.

Segundo Hooton TM e Levy SB (2001) a Haemophilus influenzae é a principal causa de várias doenças que resultam da colonização primária do trato respiratório produzindo vários fatores de colonização e virulência que permitem que o organismo se ligue às células epiteliais respiratórias e interrompa 0 movimento ciliar nas vias aéreas superiores. $O$ organismo pode então entrar em vários órgãos como extensões dessa colonização respiratória primária.

Para Roman F, et al. (2004) as medidas de prevenção e controle de infecções são os pilares da redução das tendências de resistência e precisam ser aplicadas ao Haemophilus influenzae e a todos os outros organismos. As tendências de resistência precisam ser rastreadas continuamente para orientar medidas proativas e reativas. A vigilância contínua dos determinantes de resistência a essa estirpe dos sistemas globais de vigilância será importante para monitorar e pode ajudar a prever como esse organismo pode evitar os atuais esquemas antimicrobianos.

Seguindo essa linha de raciocínio, Livermore DM (2005) desenvolveu estudos que constataram a existência de evidências de que o uso de antimicrobianos é a principal força motora para o desenvolvimento da resistência bacteriana. Como exemplo o autor destaca que as taxas de resistência são maiores em contextos de consume mais intense desses fármacos e que há frequente surgimento de resistência durante o curso da terapia, com consequente falência terapêutica.

Dellit TH, et al. (2007) por sua vez lembra que, universalmente, constata-se uma correlação temporal entre a comercialização de novos agentes e o posterior desenvolvimento de resistência microbiana aos mesmos, às vezes após curto período de sua introdução no mercado.

\section{Fatores que podem levar ao desenvolvimento da resistência microbiana}

Sabe-se da existência de inúmeros fatores e mecanismos (intrínsecos e extrínsecos) que auxiliam no processo dos micro-organismos de desenvolver resistência às drogas antimicrobianas, o que nos coloca diante da necessidade urgente de desenvolver estratégias preventivas na disseminação de resistência para serem aplicadas em todas as unidades de atendimento de saúde de nosso país.

Souza RMB, et al. (2008) descreve que, no decorrer das rotinas de muitos postos de atendimento e hospitais deste país, os erros de prescrição de antimicrobianos têm sido descritos como, desde a indicação não apropriada para infecções, até mesmo erros técnicos por parte dos prescritores em relação à duração do tratamento, dosagem, intervalo entre doses e via de administração incorreta, podendo comprometer a terapêutica do paciente.

Entretanto, para isso, defende Souza RMB et al. (2008), é preciso se considerar estudos relevantes que possam monitorar as taxas de infecções e avaliar os perfis de sensibilidade e hábitos de prescrição, uma vez que constituem uma das estratégias para monitoramento do uso de medicamentos.

Já Shab SN, et al. (2001) defende que as deficiências no registro de informações na prescrição são as responsáveis por grande parte dos erros de medicação. Nesse caso a análise de prescrição pode contribuir para uma avaliação preliminar da qualidade da terapia. Para os autores uma das formas de se controlar a qualidade do processo de prescrição é evidenciar falhas que comprometem a adesão ao tratamento e 
favorecem o aparecimento de reações adversas e falhas terapêuticas, prejudicando o esforço realizado pelo serviço de saúde para o provimento adequado de medicamentos. Em outro problema Souza RMB, et al. (2008) fala da antibiótico profilaxia, muito indicada nos procedimentos cirúrgicos passíveis de complicações graves, devido à eficácia comprovada de seu uso pela literatura específica - embora, nem por isso, escapem dos erros de prescrição no sentido de, na sua indicação, serem selecionados os antibióticos incorretos, ou o momento inexato da sua administração, a não repetição das doses durante os procedimentos prolongados, a duração excessiva da profilaxia e o uso inapropriado de antibióticos de amplo espectro.

Souza RMB, et al. (2008) lembra que a aplicação correta desses procedimentos, em especial no ambiente hospitalar, deve ser controlada pela Comissão de Controle de Infecção Hospitalar (CCIH) que, juntamente com a Farmácia, estabelecem critérios de seleção e utilização e os difundem na tentativa de minimizar o fracasso terapêutico, a toxicidade e os custos com antibióticos considerando sempre a questão da resistência microbiana.

Livermore DM (2005) vem ressaltar que o processo de resistência das bactérias a antibióticos se trata de uma resposta ao uso abusivo de antimicrobianos no meio ambiente, sendo considerado atualmente um problema de saúde pública de grande magnitude, vindo a determinar um aumento na morbidade, mortalidade e custo, principalmente, em nossos hospitais nas Unidades de Terapia Intensiva.

O Estado através da Agência Nacional de Vigilância Sanitária (ANVISA), controladora do SNGPC vem convocando alertando a sociedade para o risco do uso incorreto de antibióticos e provocando uma importante alteração cultural, baseado sempre no fato de que se trata de uma realidade que colabora de forma direta para a redução dos riscos da resistência microbiana, lembrando sempre de a mídia e o governo são peça-chave nesse processo de mudança comportamental.

Soma-se a isso o papel da indústria farmacêutica e seus bilhões de dólares de lucro ao longo de cada ano, de investor em pesquisas para o desenvolvimento de novos agentes inovadores que, por meio de mecanismos de ação originais e com maior espectro de atividade, consigam atingir micro-organismos com perfis de resistência cada vez mais complexos e nos garantam a proteção necessária diante de qualquer espécie de bactéria que possa nos afligir com seu processo infeccioso, seja ela mais ou menos resistente.

\section{Administração correta de antimicrobianos para se evitar o processo de resistência bacteriana}

Pela capacidade que possuem de eliminarem bactérias e impeder em sua mutiplicação os antibióticos são substâncias utilizadas diretamente no tratamento de infecções bacterianas diversas. Zimerman R (2010) lembra que seu surgimento tornou-se um marco na história da medicina, devido ao fato de, anterior a sua descoberta, os índices de mortalidade eram muito elevados em decorrência, principalmente, de diversos tipos de infecções que acometiam grande parte da população desde os tempos mais remotos.

Entretanto, de instrumento eficaz no tratamento de infecções bacterianas, os antibióticos passaram a grandes vilões no processo de desenvolvimento de bactérias resistentes devido ao seu uso indiscriminado, pois, mais resistentes a esses medicamentos, as bactérias acabam resistindo aos tratamentos e gerando um grave problema de saúde numa escala mundial.

Na visão de Chastre J, et al. (2013), para a maioria dos clínicos, um dos meios mais promissores para reduzir a pressão de seleção de antimicrobianos sem prejudicar a segurança do paciente tem sido cessação da terapia com medicamentos antimicrobianos em pacientes que não têm uma infecção bacteriana. $O$ autor acredita que, embora as políticas e diretrizes de medicamentos antimicrobianos não tenham sido ainda de grande ajuda na tomada de decisões individuais, de certa forma elas sensibilizaram a comunidade médica para o crescente problema de uso excessivo e resistência de drogas antimicrobianas.

Assim, destacam Trabulsi LR e Alterthum F (2011), se repetidas regularmente, as campanhas provavelmente reduzirão os pedidos inadequados de pacientes para agentes antimicrobianos, o que, em conjunto com modelos de educação médica, pode reduzir práticas inadequadas de prescrição de antimicrobianos. 
O uso inadequado dos antimicrobianos ocorre quando esses medicamentos são utilizados para o tratamento de infecções que não são causadas por bactérias (como, por exemplo, resfriados), e quando são consumidos em doses incorretas e, inclusive, num tempo de tratamento inadequado. Ou seja, uma dinâmica perigosa que Trabulsi LR e Alterthum $F$ (2011) lembram ao defenderem que o antimicrobiano não induz a resistência mas sim, é um selecionador das cepas mais resistentes existentes no meio de uma população.

Para Trabulsi LR e Alterthum F (2011) é preciso estar atento a fatores como o uso adequado de agentes antimicrobianos, obtenção de um diagnóstico preciso, determinação da necessidade e momento da terapia antimicrobiana e o devido entendimento de como a dosagem afeta as atividades antimicrobianas de diferentes agentes para adequação às características do hospedeiro, utilizando o espectro mais estreito e a menor duração da terapia e alternando a agentes orais o mais rápido possível. No Quadro 3 vemos como Wannmacher $L$ (2004) descreve de forma clara alguns pontos importantes como forma de se evitar a resistência aos antimicrobianos.

Quadro 4 - Medidas preventivas contra resistência aos antimicrobianos.

\begin{tabular}{|c|c|}
\hline Número de Ações & Medida Preventiva \\
\hline Ação 1 & Nunca usar antibióticos sem a indicação de um medico especialista ou um dentista. \\
\hline Ação 2 & $\begin{array}{c}\text { Obedecer a prescrição da dose e dos horários corretos, pois o uso de doses } \\
\text { maiores não acelera a cura. }\end{array}$ \\
\hline Ação 3 & $\begin{array}{l}\text { Nunca parar o tratamento antes do prazo indicado, mesmo que os sintomas tenham } \\
\text { melhorado ou desaparecido. }\end{array}$ \\
\hline Ação 4 & $\begin{array}{l}\text { Não usar antibióticos fora do prazo de validade, pois podem não fazer efeito e } \\
\text { favorecer a resistência bacteriana. }\end{array}$ \\
\hline Ação 5 & $\begin{array}{c}\text { Evitar guardar sobras de antibióticos em casa, pois a quantidade geralmente não é } \\
\text { suficiente para um novo tratamento. }\end{array}$ \\
\hline
\end{tabular}

Fonte: Monteiro RFS, et al., 2020. Baseado em Wannmacher L, 2004.

Diante do quadro acima, depreende-se que foi extremamente necessária a inclusão dos antimicrobianos no SNGPC como forma de coibição e controle de seu uso indiscriminado pelos riscos a que todo paciente ou pessoa comum se expõe diante do seu uso indiscriminado.

\section{CONSIDERAÇÕES FINAIS}

A resistência antimicrobiana, um desafio global à saúde pública, se acelerou pelo uso excessivo de antibióticos em todo o mundo fazendo da resistência antimicrobiana a causa de infecções graves, complicações, estadias hospitalares mais longas e aumento da mortalidade. A prescrição excessiva de antibióticos associa-se a um risco aumentado de efeitos adversos e reaparecimento mais frequente das infeções. As intervenções devem abranger a aplicação da política de proibição da venda excessiva de antibióticos, uso de programas de administração de antimicrobianos, aprimoramento das habilidades de comunicação com pacientes através de folhetos informativos e a realização de estudos mais pragmáticos na atenção primária, cujos resultados são do interesse dos médicos, como complicações e resultados clínicos.

\section{REFERÊNCIAS}

1. BERGMAN M, et al. Effect of macrolide consumption on erythromycin resistance in Streptococcus pyogenes in Finland in 1997-2001. Clin Infect Dis. 2004; 38: 1251-1256.

2. BERMAN S. Epidemiology of acute respiratory infections in children of developing countries. Rev Infect Dis 2001; 13(suppl 6):5454-62

3. BISSON MP. Farmácia Clínica e Atenção Farmacêutica. São Paulo: Medfarma, 2003.

4. BONTEN MJM, et al. Understanding the spread of antibiotic resistant pathogens in hospitals: Mathematical models as tools for control. Clinical Infectious Diseases. 2001; 33: 1739-1746.

5. CHASTRE J, et al. Comparison of 8 vs 15 days of antibiotic therapy for ventilator-associated pneumonia in adults: a randomized trial. JAMA. 2013; 290:2588-98. 
6. COSTELLOE CM, et al. Efeito daprescrição de antibióticosnos cuidados primáriossobre a resistência antimicrobianaem pacientes individuais: revisão sistemática e meta-análise. BMJ, London, 2010; 340, c2096.

7. DELLIT TH, et al. Sociedade de Doenças Infecciosas da América e sociedade de cuidados de saúde epidemiologia da América diretrizes para o desenvolvimento de um programa institucional para melhorar a administração de antimicrobianos. Clinical Infectious Diseases, Chicago, 2007; 44, 159-177.

8. FIOL FSD, et al. Perfil de prescrições e uso de antibióticos em infecções comunitárias. Revista da Sociedade Brasileira de Medicina Tropical, Uberaba, 2010; 43(1).

9. GONZALES R, et al. Excessive antibiotic use for acute respiratory infections in the United States. Clin Infect Dis. 2011; 33(6):757-762.

10. HOOTON TM, LEVY SB. Antimicrobial resistance: A plan of action for community practice. American Family Physician. 2001; 63(6): 1087-1096.

11. JENSEN US, et al. Efeito de medicamentos genéricos no preço e consumo de ciprofloxacina em cuidados de saúde primários: a relação de aumento da resistência. Journal of Antimicrobial Chemotherapy. [S. I.], 2010; 65, $1286-1291$.

12. LIVERMORE DM. A minimização da resistência aos antibióticos. Lancet Infectious Diseases. S.I., v. 5, p. 450-459, 2005.

13. OLIVEIRA AC, et al. Infecções hospitalares: Abordagem, Prevenção e Controle. Medsi, Rio de Janeiro, 1998.

14. ROMAN F et al. Dynamics of long-term colonization of respiratory tract by Haemophilus influenzae in cystic fibrosis patients shows a marked increase in hypermutable strains. J Clin Microbiol 2004; 42:1450-9.

15. ROSSI F, ANDREAZZI DB. Resistência bacteriana: interpretando o antibiograma. São Paulo: Atheneu; 2005.

16. SHAB SN, et al. Uma pesquisade erros de prescrição na prática geral. The Pharmaceutical Journal. 2001; 267, 860862.

17. SOUZA RMB, et al. Análise da antibioticoprofilaxia conforme os protocolos de uso racional de medicamentos. In: Anais do XI CongressoBrasileiro de Controle de Infecção e Epidemiologia Hospitalar, 2008, Rio de Janeiro. Rio de Janeiro: Jornal Brasileiro de Doenças Infecciosas. Sociedade Brasileira de Infectologia, 2008.

18. TRABULSI LR, ALTERTHUM F. Microbiologia. 4. ed. São Paulo: Atheneu, 2011.

19. TRABULSI LR, et. al. (Org.). Microbiologia. 3. ed. São Paulo: Atheneu, 2006.

20. VANDENBROUCKE-GRAULS CMJE. The threat of multiresistant microorganisms. Eur J Clin Microbiol Infect Dis 2003; (suppl 1):S27-30.

21. VERSPORTEN A, et al. Antibiotic use in eastern Europe: a cross-national database study in coordination with the WHO Regional Office for Europe. Lancet Infect Dis. PII: 2014; S1473-3099(14)70071-4.

22. WANNMACHER L. Uso indiscriminado de antibióticos e resistência microbiana: uma Guerra perdida? Uso racional de medicamentos: temas selecionados. 2004; 1(4): 1-6.

23. WHO. World Health Organization. Dia Mundial da Saúde. Abril de 2011. Disponível em: www.who.int/world-healthday/2011/es. Acesso em 2020.

24. WHO. World Health Organization. World Health Organization Report on Infectious Diseases 2011 - Overcoming antimicrobial resistance. World Health Organization 2000 Publication Code: WHO/CDS/2000.2.

25. ZIMERMAN RA. Uso Indiscriminado de Antimicrobianos e Resistência Microbiana. Horus (Sistema Nacional de Gestão da Assistência Farmacêutica), 2010. 